\title{
The origin of deep ocean microseisms in the North Atlantic Ocean
}

\author{
By Sharon Kedar ${ }^{1, *}$, Michael Longuet-Higgins ${ }^{2}$, Frank Webb ${ }^{1}$, \\ Nicholas Graham ${ }^{3}$, Robert Clayton ${ }^{4}$ and Cathleen Jones ${ }^{1}$ \\ ${ }^{1}$ Jet Propulsion Laboratory, California Institute of Technology, \\ Pasadena, CA 91109, USA \\ ${ }^{2}$ Institute for Nonlinear Science, University of California, San Diego, \\ La Jolla, CA 92093-0402, USA \\ ${ }^{3}$ Hydrologic Research Center, San Diego, CA 92130-2069, USA \\ ${ }^{4}$ Seismological Laboratory, California Institute of Technology, \\ Pasadena, CA 91125-2100, USA
}

Oceanic microseisms are small oscillations of the ground, in the frequency range of 0.05- $0.3 \mathrm{~Hz}$, associated with the occurrence of energetic ocean waves of half the corresponding frequency. In 1950, Longuet-Higgins suggested in a landmark theoretical paper that (i) microseisms originate from surface pressure oscillations caused by the interaction between oppositely travelling components with the same frequency in the ocean wave spectrum, (ii) these pressure oscillations generate seismic Stoneley waves on the ocean bottom, and (iii) when the ocean depth is comparable with the acoustic wavelength in water, compressibility must be considered. The efficiency of microseism generation thus depends on both the wave frequency and the depth of water. While the theory provided an estimate of the magnitude of the corresponding microseisms in a compressible ocean, its predictions of microseism amplitude heretofore have never been tested quantitatively. In this paper, we show a strong agreement between observed microseism and calculated amplitudes obtained by applying Longuet-Higgins' theory to hindcast ocean wave spectra from the North Atlantic Ocean. The calculated vertical displacements are compared with seismic data collected at stations in North America, Greenland, Iceland and Europe. This modelling identifies a particularly energetic source area stretching from the Labrador Sea to south of Iceland, where wind patterns are especially conducive to generating oppositely travelling waves of same period, and the ocean depth is favourable for efficient microseism generation through the 'organ pipe' resonance of the compression waves, as predicted by the theory. This correspondence between observations and the model predictions demonstrates that deep ocean nonlinear wave-wave interactions are sufficiently energetic to account for much of the observed seismic amplitudes in North America, Greenland and Iceland.

Keywords: microseisms; wave-wave interaction; acoustic resonance; wave model; Stoneley waves

* Author for correspondence (sharon.kedar@jpl.nasa.gov). 


\section{Introduction}

Microseisms are omnipresent energy recorded by seismometers over a broad range of periods. Oceanic microseisms are a particularly energetic type of microseisms occurring in the frequency band of $0.1-1.0 \mathrm{~Hz}$, and usually dominated by wave periods of $5-7 \mathrm{~s}$, which are associated with high ocean waves of half their frequency. In a fundamental paper, Longuet-Higgins (1950) showed that the corresponding ocean surface wave-wave interaction could, under suitable conditions, cause pressure oscillations at double the frequency of the ocean waves, resulting in seismic wave generation at the ocean floor. It was shown that at shallow depths, where the propagation time of a compression wave from the ocean surface to the bottom is small relative to the ocean wave period, the compressibility of the water can be ignored, resulting in a simple formulation of the pressure forcing function. This incompressible formulation of the theory was verified in laboratory experiments on periodic surface gravity waves by Cooper \& Longuet-Higgins (1951), and numerous studies have used the theory to confirm the causal relationship between the ocean and the seismic waves that they generate at double their frequencies. For larger depths, however, Longuet-Higgins (1950) developed a more complete formulation of the theory, which included the compressibility of the water. This predicted the magnitude of the vertical displacement of the ocean floor associated with the Stoneley waves (seismic surface waves which propagate along the solid-fluid interface) caused by an ocean wave field containing opposing wave components. The theory accounts for the wave-wave interaction at any point in the ocean, that is, the analysis is not limited to a local storm or 'fetch' area, and therefore is not restricted to the frequency distribution of waves in the area of wind-wave generation. A different approach was taken by Hasselmann (1963), who calculated the displacement of the seabed due to local waves, and by Webb (1992), who used Hasselman's formulation to model the statistical properties of the observed microseisms (for a review of theoretical treatments of the problem, see Kibblewhite \& Wu (1996)). Although the results of a number of studies have confirmed that, as predicted by the theory, the wave-wave interaction mechanism is the key physical process behind seismic observations, a quantitative test of the compressible part of the theory has never been carried out. This is the focus of the present study.

Since 1950, many studies have sought to locate the regions of the oceans that are responsible for generating microseisms. A variety of observations and techniques have been employed with varying degrees of success though it appears that the pressure source of ocean microseisms has never been directly measured or quantitatively estimated. With few exceptions, most of these studies used data from continental seismic stations with a focus on particular coastal regions. Such studies using near coastal seismometers in southern California (e.g. Haubrich et al. 1963; Tanimoto et al. 2006) and buoys and ocean bottom seismometers along the Oregon coast (Bromirski \& Duennebier 2002) have suggested nearby and near-shore coastal sources. Analyses of larger seismic networks have suggested that the microseism sources may, at times, be at great distances from the seismic networks that record them. Data on the directional properties of seismic surface waves (Cessaro 1994) from three North American seismic arrays have indicated that the source regions of several microseismic episodes lay offshore of western continental North America and in the Labrador Sea. A similar 
analysis of surface wave polarization from seismic arrays in southern California (Schulte-Pelkum et al. 2003) showed that seismic surface waves typically arrive from the direction of the nearby Pacific coastlines, but on occasion the waves arrive from the general direction of the Labrador Sea and North Atlantic Ocean, during episodes of high seas in that region. Polarization studies have also implicated high seas and storm waves in the generation of miscroseisms in California from hurricane Katrina (Gertstoft et al. 2006). However, statistical analysis and seismic polarization studies remain uncorroborated by either the ocean-wide observations of wave-wave interactions that are predicted to be required by the theory or by quantitative predictions of the seismic amplitudes.

In the absence of definitive observations of regions of wave-wave interaction in the open ocean, some studies have used correlations between the wave heights derived from wave action models (WAMs) and continental seismic observations (Essen et al. 2003), ocean bottom observations (Dahm et al. 2006), or barometric observations of the atmospheric equivalent of microseisms known as microbaroms (Evers \& Haak 2001; see Arendt \& Friits (2000) for a recent theoretical treatment of microbaroms). In general, these studies found good correlation between seismic amplitudes and wave heights, suggesting a causal relationship between ocean swell and microseisms. Yet, without identifying the wave spectra of the wave fields in these regions where opposing waves interact, the location of the microseisms' source remains unconfirmed.

Analysis of observations from the ocean bottom seismic station $\mathrm{H}_{2} \mathrm{O}$ near Hawaii (Bromirski et al. 2005) has shown that local winds produced only highfrequency microseisms, which attenuated quickly and did not reach coastal areas, whereas the main sources of microseisms at that site during the period of observation appeared to emanate from coastal regions of the northeast Pacific Ocean. In contrast, analyses from the Atlantic Ocean have located the source of microseisms in the deep North Atlantic Ocean and have linked them to the movement of cyclones in that region (Tabulevich et al. 1976, 1990; Tabulevich 1992). The observations of Stehly et al. (2006) also suggest that the 5-10 s seismic energy in the Atlantic Ocean originates in the deep North Atlantic during winter months. Cessaro (1994) has located microseisms generation regions up to $1000 \mathrm{~km}$ offshore, far from areas where coastal generation processes could dominate.

Few, if any, studies have sought to simulate quantitatively either the spatially distributed generation of microseisms using ocean wave information from models or from observations, or the resulting signals that would be expected at seismographic stations. Without physically measuring or modelling the source of microseisms, that is, the intensity of wave-wave interaction throughout the ocean, the degree of success of previous attempts to locate the microseism source regions cannot be quantified. The following represents a first attempt to model ocean-wide wave-wave interaction intensities from wave model hindcasts and use them in a quantitative test of the fully compressible theory, as formulated by Longuet-Higgins (1950).

\section{(a) Theory}

We provide here a brief summary of the Longuet-Higgins theory highlighting the main equations used in this study. For clarity, we use the same notations as used in the original paper. 
First, when two regular trains of waves travelling in opposite directions with amplitudes $a_{1}$ and $a_{2}$ and radian frequency $\sigma$ interact, it can be shown that they result in a pressure oscillation, $\bar{p}$, of double the frequency $(2 \sigma)$

$$
\frac{\bar{p}-p_{0}}{\rho}-g h=-2 a_{1} a_{2} \sigma^{2} \cos (2 \sigma t)
$$

where $\rho$ is the fluid density; $h$ is the fluid depth; and $p_{0}$ is the ambient hydrostatic pressure. $\sigma$ is related to depth $h$ and wavenumber $k$ by the dispersion relation

$$
\sigma^{2}=g k \tanh (k h) \text {. }
$$

Unlike the space-periodic pressure fluctuation, which decays rapidly with depth, the space-averaged pressure oscillation of the right side of equation (1.1) is independent of depth. Hence when the depth $h$ exceeds half a wavelength it becomes the dominant pressure oscillation. Moreover, it is in phase at all horizontal positions over which the waves of frequency $\sigma$ extend. Note that wave amplitudes $a_{1}$ and $a_{2}$ need not be equal as in a standing wave, but, when either $a_{1}$ or $a_{2}$ vanishes, we obtain a single progressive wave in which the unattenuated term vanishes. Equation (1.1) was confirmed by careful experiments in a laboratory wave channel (Cooper \& Longuet-Higgins 1951). Moreover, it was found that equation (1.1) could be used to measure the reflection coefficient from a partial vertical barrier.

The ocean wave field is typically not monochromatic; rather, it is generally composed of waves of different periods travelling in different directions. Longuet-Higgins (1950) introduced into ocean wave analysis the idea of a continuous energy spectrum (a directional spectrum) in two horizontal coordinates $(x, y)$ in which each element $d \boldsymbol{k}$ in wavenumber space $\boldsymbol{k}=\left(k_{x}, k_{y}\right)$ makes a contribution to the total wave energy proportional to $E(\boldsymbol{k}) d \boldsymbol{k}$, where $E(\boldsymbol{k})$ is the (given) energy spectral density. He demonstrated that only the pairs of wave components with nearly opposite wavenumbers $\boldsymbol{k}$ and $\boldsymbol{-} \boldsymbol{k}$ (i.e. waves of the same period propagating in opposite directions) produced the unattenuated, double-frequency pressure oscillations.

If the ocean is modelled as a compressible fluid layer of uniform depth $h$, overlying a semi-infinite elastic medium (the 'seabed'), then such a combined system can support elastic waves (Stoneley waves) whose wavelength, at any given frequency, is very large compared with that of the ordinary ocean surface waves (i.e. gravity waves) of half that frequency.

To calculate the vertical displacement of the ocean floor due to a given field of gravity waves, Longuet-Higgins (1950) showed that a term analogous to the unattenuated pressure of equation (1.1) could be assumed to be applied to the upper surface of the ocean, that is, to the fluid part of the system. Owing to the compressibility of the fluid, however, the elastic response of the seabed to this excitation in the fluid medium is dependent on the total depth $h$ of the fluid layer.

Eqn 198 of Longuet-Higgins' paper indicates that, if two nearly opposite trains of ocean surface waves with r.m.s. amplitudes $a_{1}$ and $a_{2}$ interact over a horizontal area, $\Lambda$, that is large enough to contain several groups of waves, then the r.m.s. displacement of the sea floor at a great distance $r$ from the centre of the generation area is given to an order of magnitude by

$$
\delta \cong 4 \pi \rho a_{1} a_{2} \sigma_{12}^{2}\left(\Lambda \frac{\Omega_{12}}{\Omega_{1} \Omega_{2}}\right)^{1 / 2} \bar{W}\left(2 \sigma_{12}, r\right) \mathrm{e}^{2 \mathrm{i} \sigma_{12} t},
$$




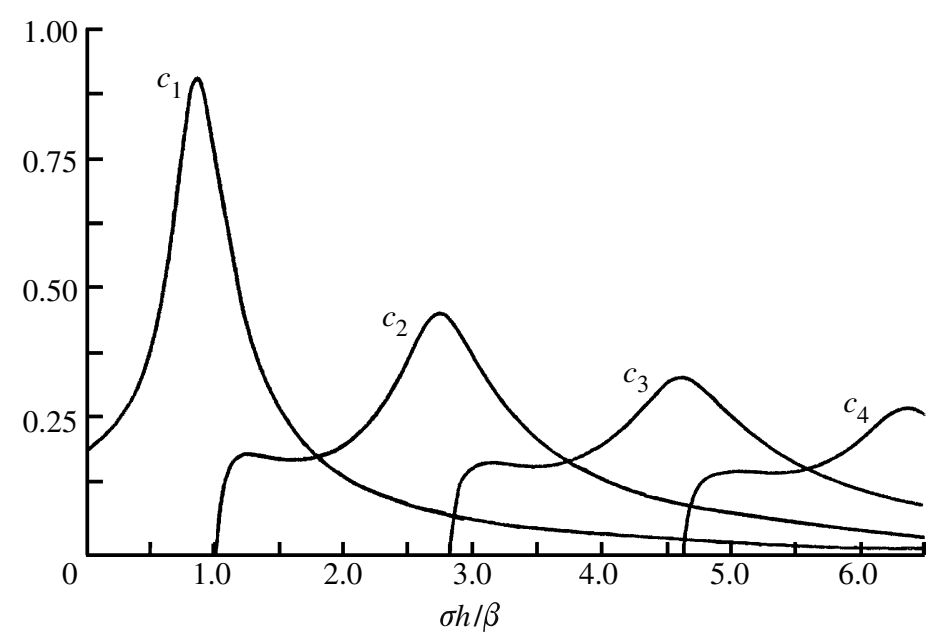

Figure 1. The coefficients $c_{1}, c_{2}, c_{3}$ and $c_{4}$ in equation (1.4) are shown as functions of $\sigma h / \beta$, where $\sigma$ is the radian frequency of the surface gravity waves, $h$ is the total depth of water and $\beta$ is the shear velocity in the underlying elastic medium. $\beta$ is taken as $2.8 \mathrm{~km} \mathrm{~s}^{-1}$, approximately twice the speed of sound in water (from Longuet-Higgins 1950).

where $\Omega_{1}$ and $\Omega_{2}$ are the areas of wavenumber space corresponding to the two wave groups; $\Omega_{12}$ is the area of overlap between $\Omega_{1}$ and $-\Omega_{2}$ (the reflection of $\Omega_{2}$ in the origin); and $\sigma_{12}$ is the radian frequency of the wave in $\Omega_{12}$. If there is no overlap, $\Omega_{12}$ is zero and the microseisms (i.e. the Stoneley waves) are not excited. $W$ is the response function of the water-solid system to a pressure oscillation of frequency $2 \sigma$ applied at the sea surface. (Note that $\delta$ is a function of wave frequency. Thus, the total microseism energy generation at a point is the integral of $\delta^{2}$ across a defined range of frequencies.) It was shown that

$$
\bar{W}\left(2 \sigma_{12}, r\right)=\frac{\sigma_{12}^{2}}{\rho^{*} \beta^{5 / 2}(2 \pi r)^{1 / 2}}\left[\sum_{m=1}^{N} c_{m}^{2}\right]^{1 / 2},
$$

where $\rho^{*}$ and $\beta$ are the density and shear velocity of the elastic medium, respectively, and $c_{m}(h, \sigma, \beta)$ represents a discrete mode of elastic excitation dependent upon the ratio $\sigma h / \beta$. As seen in figure 1 , these functions display resonant behaviour when the ocean depth is close to $1 / 2(m-1)+1 / 4$ of an acoustic wavelength in water, where $m$ is an integer. As pointed out by Longuet-Higgins (1950, p. 34), ' $\ldots$ the microseism amplitudes may be increased by a factor of order 5 owing to the greater response of the physical system for certain depths of water. In practice, with an ocean of non-uniform depth, the amplitude will be affected by the depth of water at all points between the generating area and the observing station. Since, however, the energy density is greatest near the source of the disturbance, the depth of water in the generating area itself may be expected to be of the most importance.' In our calculations, we model $\bar{W}$ using measured ocean bathymetry (ETOPO2; Smith \& Sandwell 1997) over an elastic Poissonian half-space with shear velocity $\beta=2800 \mathrm{~m} \mathrm{~s}^{-1}$.

The local geological structure at a continental recording station is of course not the same as at a point in the ocean. The theory assumes that the energy flux of the seismic surface waves across a vertical plane is conserved, apart 
from scattering effects. The relation of the vertical displacement in terms of the energy flux depends also on the local group velocity, but these differences are ignored here.

\section{(b) Simulation of microseisms generation with WAMs}

To hindcast the ocean wave spectrum, we used the US National Centers for Environmental Prediction (NCEP) Third-Generation WAM Wavewatch III (Tolman 1999, 2005) implemented over the North Atlantic and North Pacific oceans $\left(1.0^{\circ} \times 1.5^{\circ}\right.$ latitude-longitude spatial resolution) and drove it with 6 hourly wind data from the NCEP atmospheric reanalysis project (Kalnay et al. 1996); the output was extracted from the model at 3 hour intervals. The intensity of the wave-wave interaction is calculated from the wave spectrum. It is important to note that large-scale wave models treat the ocean-continent edges as absorbing boundaries, so they cannot account for the interactions of reflected waves with the incoming swell. Therefore, the modelled wave-wave interaction intensities contain contributions only from the deep ocean interactions.

When the wave model is run, the state of the wave field is collectively defined by the directional energy spectra at all the model grid points. The wave-wave interaction intensity is calculated from these directional spectra, as a function of both position and time. We begin by expressing $\Omega_{i}$ in terms of the wave energy density $E_{i}(\sigma)$

$$
1 / 2 a_{i}^{2}=E_{i} \Omega_{i} .
$$

Substituting the expression for the energy density into equation (1.3) and assuming that each patch of ocean is statistically independent from the others, the energy in a given frequency range is summed to obtain the following equation for the mean square ground displacement in terms of the modelled quantity $E_{1} E_{2} \Omega_{12}$ :

$$
\bar{\delta}(\sigma)^{2} \cong 64 \pi \sigma^{4} \sum_{i}\left(\Lambda E_{1} E_{2} \Omega_{12}\right) \rho^{2} \bar{W}^{2} .
$$

The sum includes the contributions from all opposing directional spectrum elements, $i$, in the frequency range $(\sigma, \sigma+\Delta \sigma)$.

The desired wave-wave interaction intensity, $\Psi$, is defined as

$$
\Psi \equiv E_{1} E_{2} \Omega_{12} .
$$

This wave-wave interaction intensity is directly derivable from the WAM directional spectra. At each grid point, the directional spectrum of the wave energy was integrated across the frequency range of $0.07-0.15 \mathrm{~Hz}$ to generate total wave-wave interaction intensity maps. According to theory, microseisms are predominantly generated in regions of high $\Psi$. In the example shown in figure $2 a$, note the opposing wave energy from the northeast and southwest at wave periods of approximately $12 \mathrm{~s}$. The high opposing wave energy results in part from the southward deflection and acceleration of the wind field around the low-pressure system centred south of Greenland by the high terrain of southern Greenland, a phenomenon associated with the production of the Greenland 'reverse tip jet' (Moore \& Renfrew 2005). 
(a)

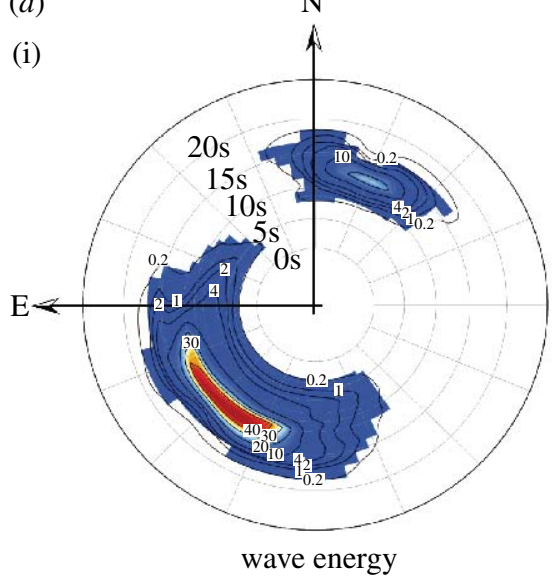

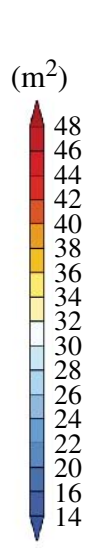

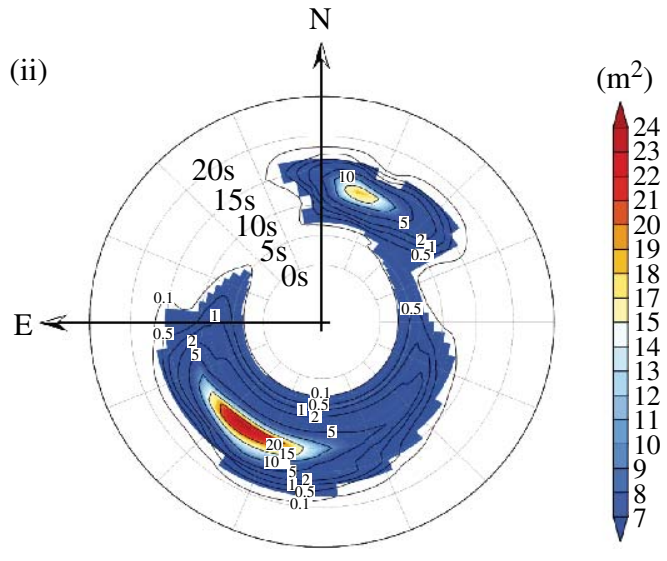

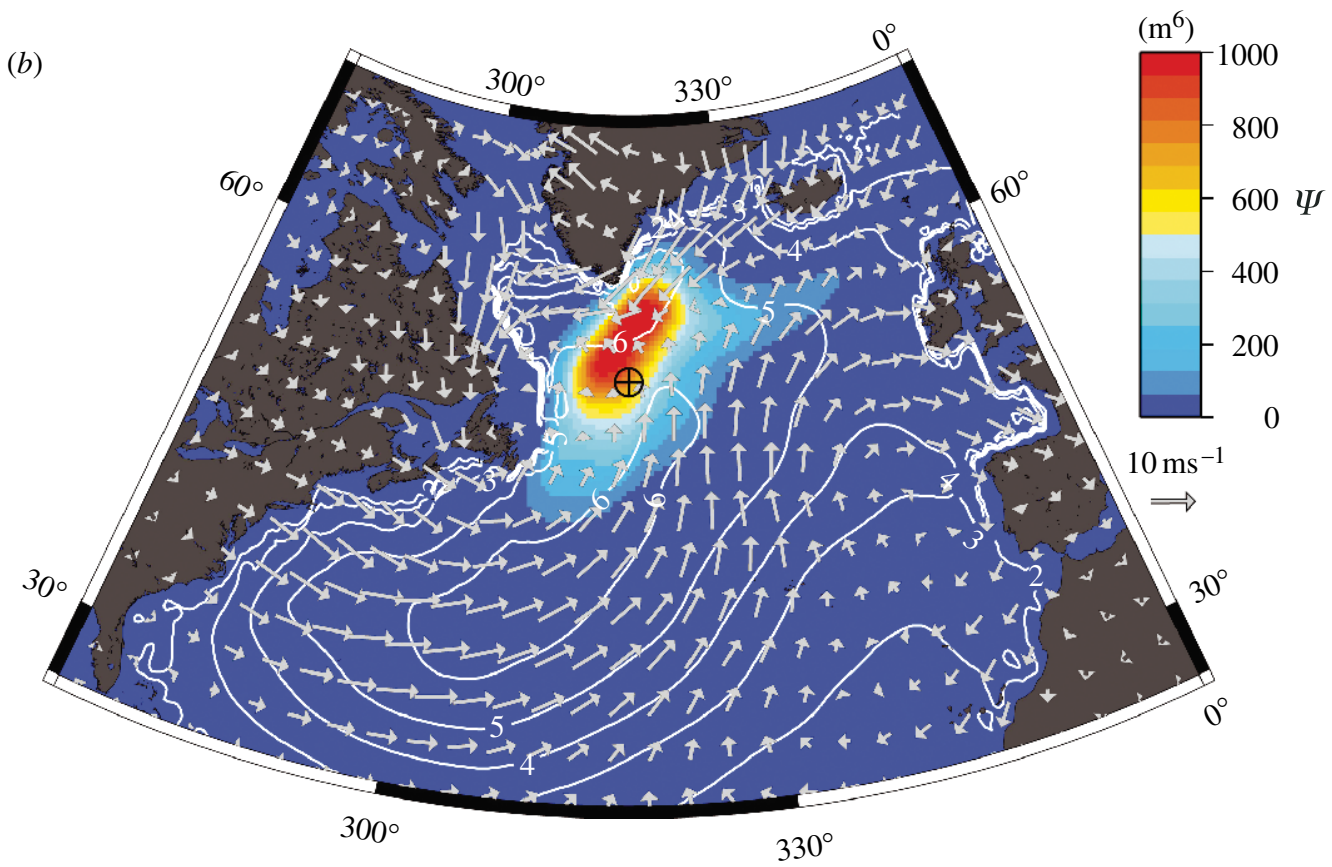

Figure 2. Wave-wave interaction intensity, $\Psi$, derived from wave directional spectra. (a) An example of a directional spectrum calculated at $53^{\circ} \mathrm{N} 42^{\circ} \mathrm{W}$ averaged over the period $(a(\mathrm{i})) 17$ January 2004, 00.00 UTC and (a(ii)) between 15 and 19 January 2004, 00.00. (a(i)) A snapshot (3 hour time window) of the directional spectrum at the point marked by a cross hair in (b). (a(ii)) The 4 day average at the same point. Frequency increases from the origin along radial lines, the wave azimuth direction is measured along concentric circles and the wave amplitude is portrayed by colour scale. Such directional spectra are used for the calculation of the wave-wave interaction intensity as described in the text. According to theory (Longuet-Higgins 1950) opposing energy of similar frequency content, as displayed here, is a necessary condition for the generation of ocean microseisms. (b) A map showing average wave-wave interaction intensities, $\Psi$, wind directions and amplitudes (arrows), and contours of significant wave heights, $H_{\mathrm{s}}$ (white lines), between 15 and 19 January 2004. Note that the peak of wave-wave interaction intensities does not necessarily coincide with the peak in the wave heights. 
(a)

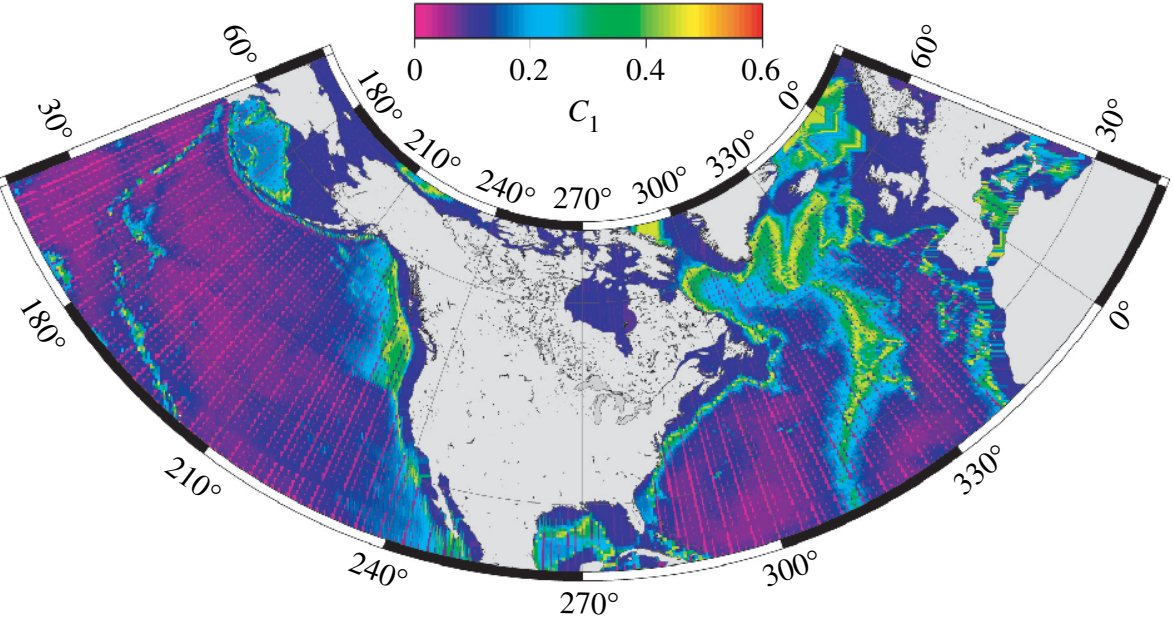

(b)

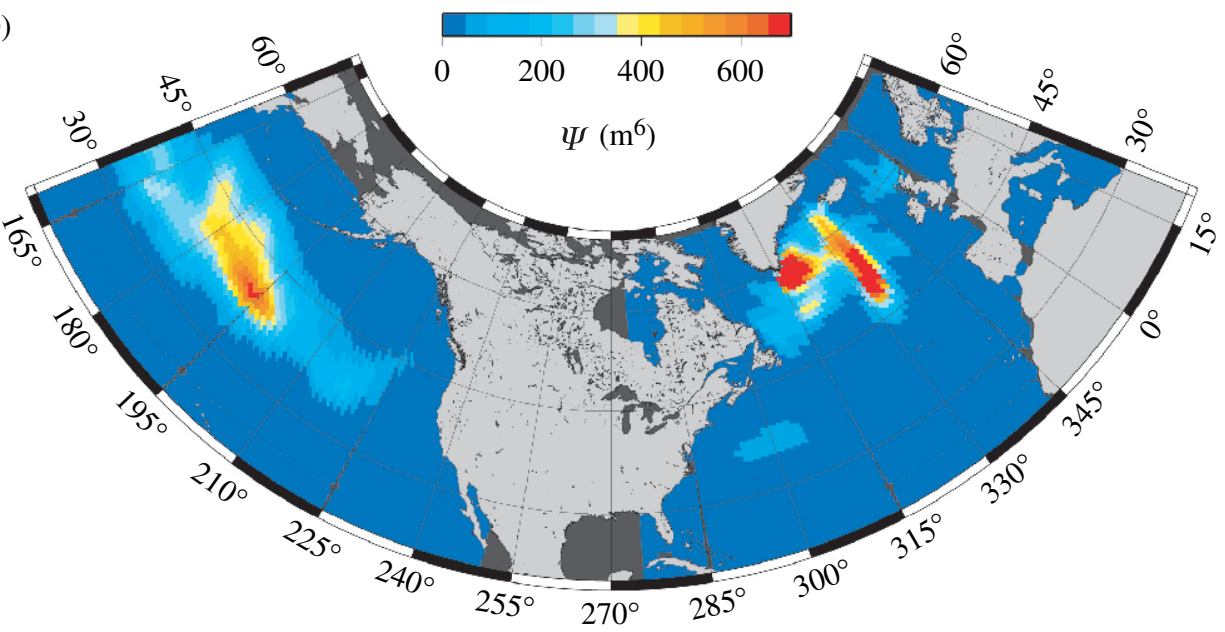

(c)

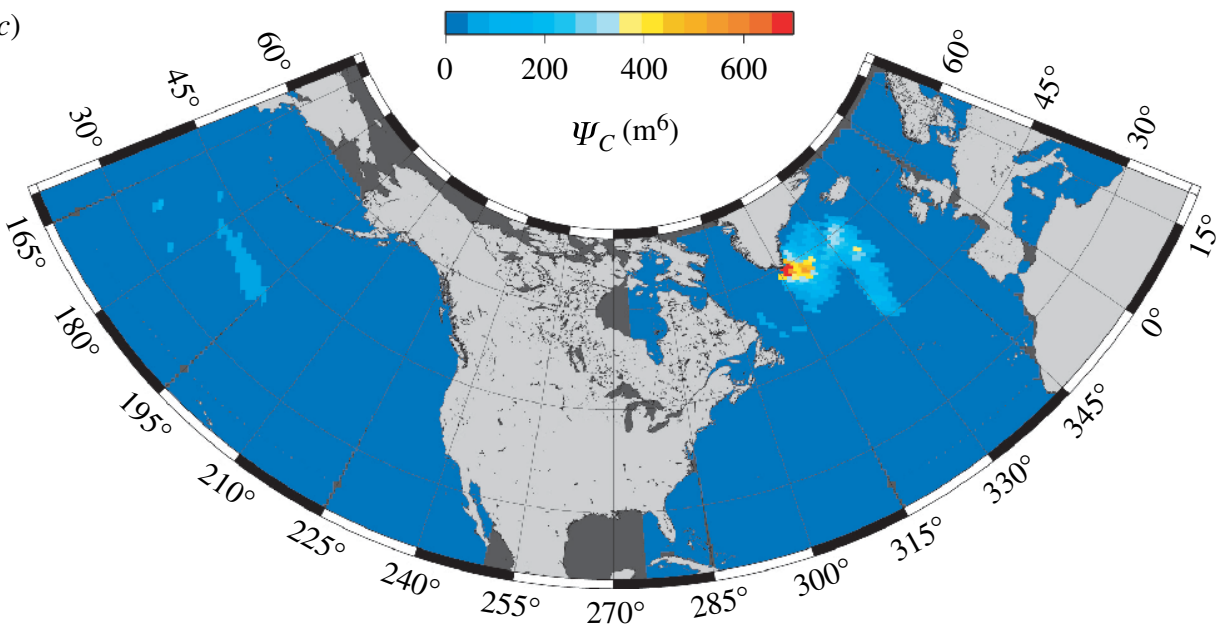

Figure 3. (Caption opposite.) 
Figure 3. (Opposite.) Microseisms generation intensity modulated by depth frequency-dependent excitation, November 2003. (a) The excitation function of half-period microseisms of the acoustical wave's first excitation mode $\left(C_{1}\right)$ at periods of 3-7 s was calculated based on ocean ETOPO2 bathymetry data. Regions of high microseisms excitation potential in the deep ocean become apparent. Wave-wave interactions in these regions will be most effective in generating microseisms should opposing wave fields of appropriate frequencies persist over them. (b) A map of the wave-wave interaction intensity, $\Psi$, derived from WAM in the North Atlantic and North Pacific oceans averaged over the month of November 2003, for wave periods of 6-14 s. Intense regions of wave-wave interaction dominate the Atlantic Ocean whereas the intensity is somewhat lower and more diffuse in the Pacific Ocean. (c) The wave-wave intensity map (b) is multiplied by the microseisms excitation potential map $(a)$ to obtain an averaged deep ocean microseisms source intensity map. A dominant source region at the southern tip of Greenland and south of Iceland remains, while the diffuse source in the Pacific is weakened substantially.

Once the wave-wave interaction intensity is derived, the water depthdependent excitation of the acoustic wave that is generated by the wave-wave interaction is calculated using equation (1.4). The combined effect of wave-wave interaction and bathymetry-modulated excitation is expressed by the quantity

$$
\Psi_{C}=\Psi \sum_{m=1}^{N} c_{m}^{2} .
$$

Figure 3 illustrates how bathymetry modulates the excitation of microseisms. Certain ocean regions, such as the Labrador Sea, the North Atlantic region south of Greenland, and the northwest Pacific coast of North America are of favourable depths for acoustic resonance at the microseisms' periods. As shown in figure 3, the strongest and most consistent excitation of microseisms occurs when the wave-wave interaction takes place over such regions. Thus, the deeper North Pacific Ocean would be inefficient in generating deep ocean microseisms. In contrast, in the North Atlantic regions noted above, climate conditions and bathymetry combine to produce a potent source. In the following discussion, we explore whether these WAM-predicted deep ocean sources are sufficiently energetic to account for the observed amplitudes of the microseisms.

Note that the accuracy of the calculated interaction intensities depends upon the accuracy of the wave model and the accuracy of the winds that drive it. Modern wave models give excellent results when driven with reanalysis winds, with correlations between observed and measured wave height of approximately 0.9 for 6 hourly data and little systematic bias (Caires et al. 2004). Moon et al. (2003) have shown a similar level of agreement for simulated and measured directional wave spectra.

\section{Time dependence of microseisms in the North Atlantic Ocean}

Figure 4 shows the distribution and amplitudes of measured ground displacements throughout North America averaged over the entire month of November 2003. Microseismic amplitudes recorded throughout northeastern North America were substantially higher than along the west coast of the continent. Figure 4 also reveals that microseismic amplitudes measured along the Pacific coast decay rapidly away from the coasts, while in the Atlantic they are of greater magnitude and propagate much further into the continent. Calculations show that this effect is too large by an order of magnitude to be accounted for by known attenuation 


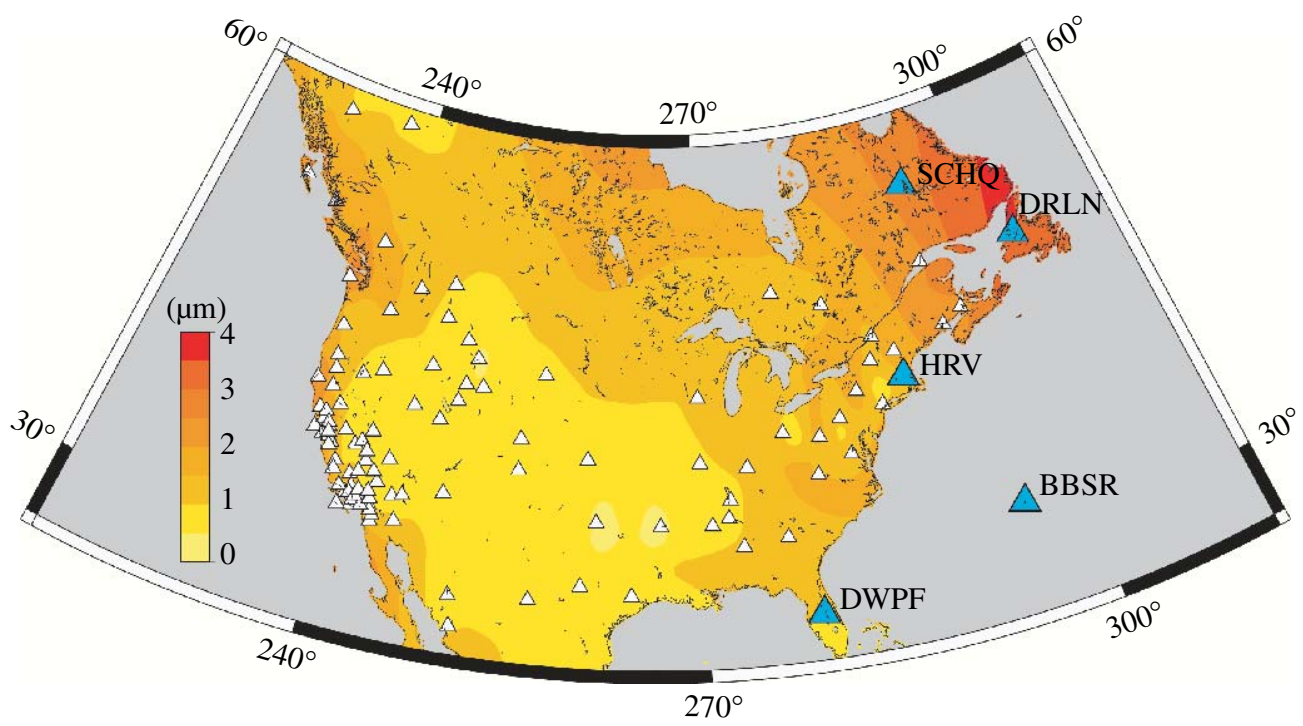

Figure 4. Average ground displacements throughout North America. The map shows the average vertical ground displacement throughout North America during 1-30 November 2003. The stations used for the displacement measurements are marked by triangles. The stations marked by blue triangles were used for the 6-month test depicted in figure 6 . Large earthquakes have been removed from the seismic dataset during this period.

differences between the western and eastern North America (Mitchell 1975). These observations, in conjunction with the observations made in figure 3 , seem to suggest that microseisms along the western North America coast are probably dominated by the coastal reflection mechanism, which is unaccounted for in the wave model. Hence, the process described above cannot be used to model and test the generation of microseisms in the Pacific Ocean, until the coastal interaction effects have been satisfactorily included in the model.

Since the bulk of the microseismic energy is in polarized seismic surface waves, a simple approximate test of the predicted source location can be made by comparing with that inferred from projected back azimuths to the source as measured at surrounding seismic stations. Figure $5 a$ combines the effects of wave-wave interaction during the peak of a microseismic episode, and scaling by the bathymetry-controlled microseisms potential (as in figure $3 c$ ). This suggests an intense source south of Greenland. The location of the model-predicted microseismic source at the southern tip of Greenland is in good agreement with the observed amplitudes and directions of propagation of the Rayleigh waves (seismic surface waves) at seismic stations around the North Atlantic. In contrast, the apparent source of microseismic energy does not correlate with the peak in ocean wave heights (figure $5 b$ ).

Next, we calculate the vertical ground displacements, and compare them with measurements at seismic stations over time (equation (1.6)). This is the first such quantitative comparison between simulated and observed ocean microseismic amplitudes, and is done here at stations of varying distances from the predicted source over the autumn and winter of 2003-2004, when microseismic activity is high. The vertical ground displacement amplitudes were compared with model 

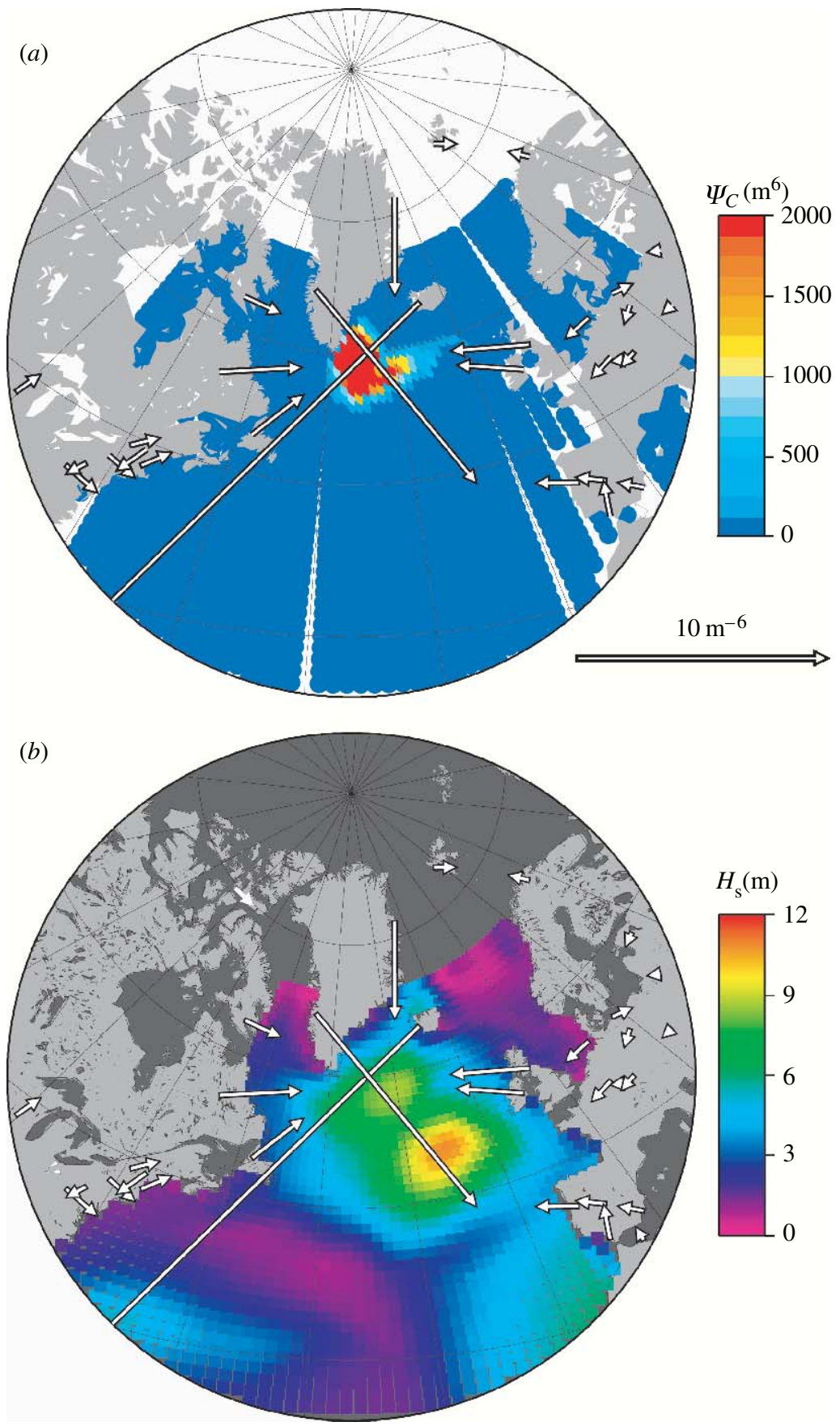

Figure 5. (Overleaf.)

calculations in the double-frequency band of $0.14-0.3 \mathrm{~Hz}$, which spans the bulk of the microseismic energy. The simulated station vertical ground displacements were calculated by adding the mean-squared wave model-based microseismic energy contributions from the entire ocean (equation (1.6)), during the period 
Figure 5. (Overleaf.) Qualitative comparison of data and modelled deep ocean sources, 1 November 2003, 00.00. (a) The modelled microseisms excitation function (wave-wave interaction intensity) and measured Rayleigh wave amplitudes and polarities during the peak of a microseisms episode in the North Atlantic. Vectors indicate the direction of Rayleigh wave arrivals at the seismic stations, determined from cross correlations of the horizontal and vertical seismic wave components with the vertical component during the 3 hour period corresponding to the same period in the wave model. A gnomonic projection, in which great circles appear as straight lines, is chosen. Vector lengths are proportional to the averaged measured vertical ground displacement. The amplitude pattern and the seismic wave directions around the North Atlantic both suggest the seismic energy emanates from a deep ocean source located south of Greenland. This is consistent with the model, which places an intense source in the same region. (b) The significant wave heights $H_{\mathrm{s}}$ during the same time period. There is little correspondence between the regions of high waves and the arrival direction of the seismic waves.

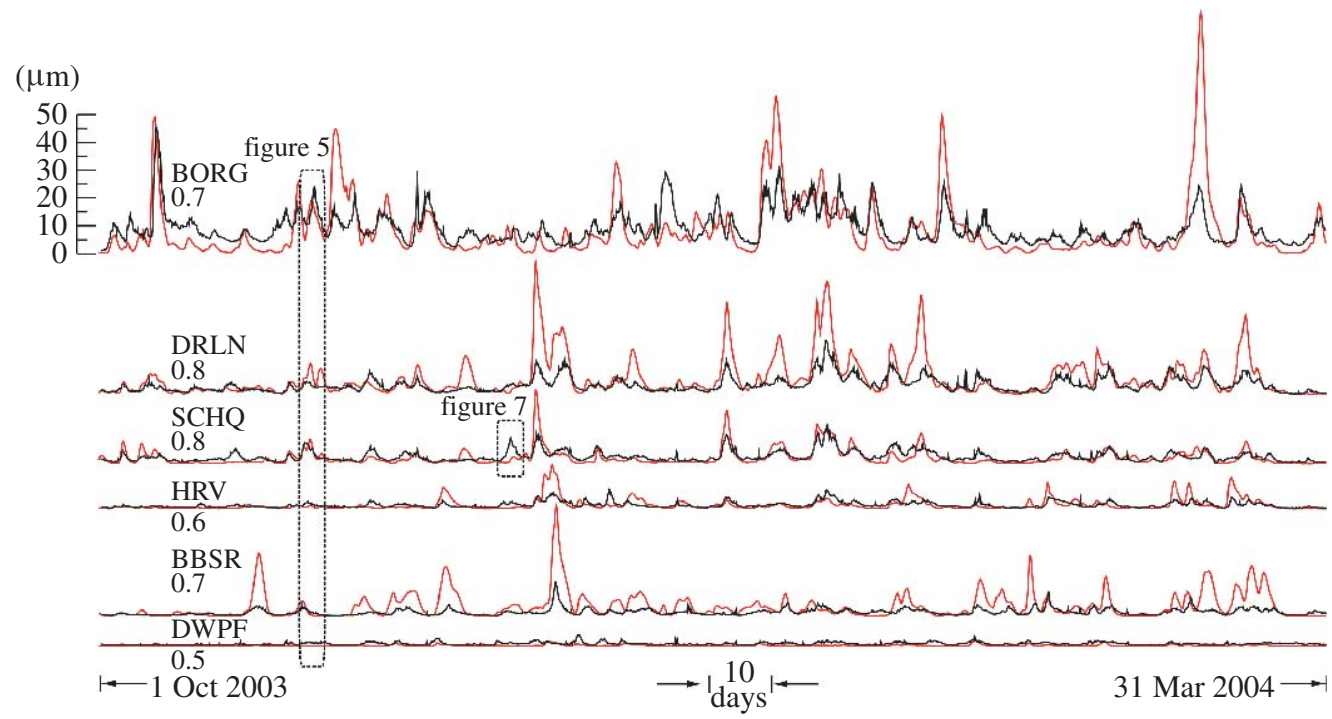

Figure 6. Quantitative comparison of measured and modelled ground displacements. A comparison between modelled vertical ground displacements using the model (red lines) and data of ground amplitudes (black lines) performed over the autumn and winter of 2003-2004, at the sites marked in figure 4 (station BORG is located in Iceland). The seismic station names and the corresponding correlation coefficients are indicated. The storms analysed in figure 5 are indicated. As discussed in figure 7, the underestimation of the microseism episode at station SCHQ is caused by incorrect specification of the edge of the sea ice.

from 1 October 2003 to 31 March 2004. The calculated vertical ground motion at a point of interest is compared with the average vertical ground motion measured during the same 3 hour period after large earthquakes were removed from the measured data. In the calculations, seismic wave propagation time differences are neglected because they are much shorter than the 3 hour time step of the model. Three-dimensional propagation effects such as multipathing and scattering, which are significant for short period (5-10 s) Rayleigh waves, are not taken into account explicitly. Rather, these effects are accounted for by selecting an attenuation factor $(Q=125)$ in agreement with the known attenuation and scattering of short-period (5-10 s) Rayleigh waves (Mitchell 
(a)

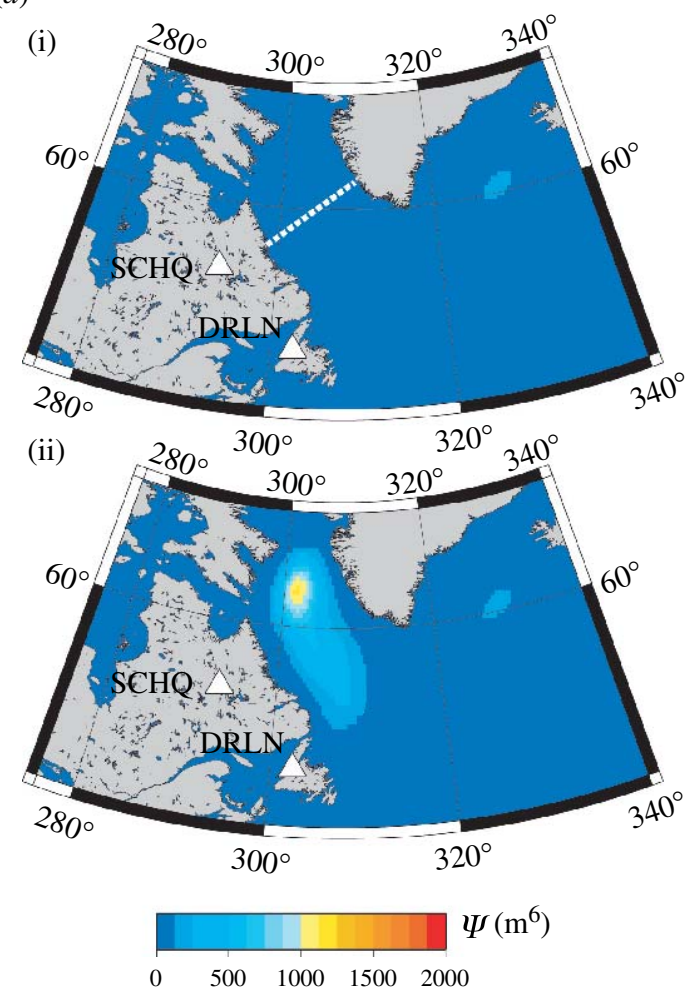

(b)

(i)

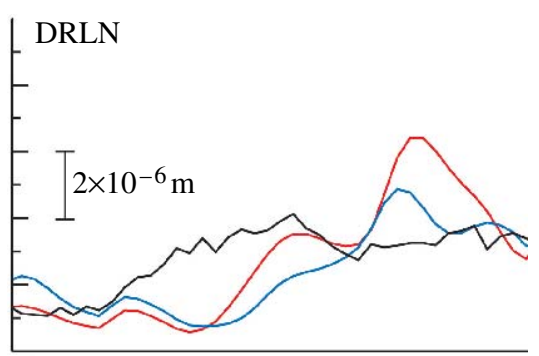

(ii)

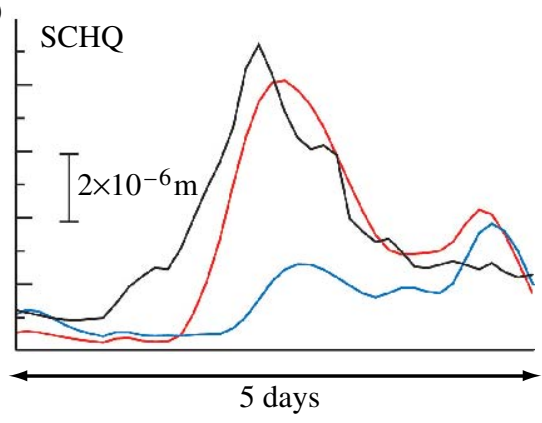

Figure 7. The importance of the precise location of the sea ice edge. Estimations of $\Psi(a(\mathrm{i}))$ with (sea ice edge used in the model is marked by the broken line) and (a(ii)) without sea ice are displayed. (b) The corresponding data (black lines) and the model with sea ice (blue lines) and without sea ice (red lines) are displayed. A local episode of microseisms would be mismodelled if the sea ice edge is placed at the wrong location. As demonstrated here, removing the sea ice from the Labrador Sea causes a local high $\Psi$ to appear in the vicinity of station SCHQ. The stations are marked by triangles.

1973, 1975; Mitchell et al. 1976; Canas \& Mitchell 1981; Langston 1989). In addition to the above approximations, other sources of mismodelling may include inaccurate location of the sea ice edge (which will be discussed below), the use of a simplified Earth model, and the omission of any sources due to coastal reflection (which may play a significant role in regions such as the steep Labrador coast). Nonetheless, as seen in figure 6 , the model does remarkably well in estimating both the timing and the maximum amplitude of the vertical ground motion during microseismic episodes observed in eastern North America, providing a first-order quantitative confirmation of the theory. It also establishes that deep ocean wave--wave interactions in the North Atlantic generate sufficient energy to account for the observed seismic amplitudes.

\section{(a) The effect of the receding sea ice on microseisms excitation}

An additional unexpected validation of the theory came from the analysis of seismic data near the North Atlantic winter sea ice. In the course of this study, it was found that observations of microseisms at seismic stations in proximity 
to the edge of the sea ice are particularly sensitive to the precise location of the ice-water boundary. Figure 7 describes this effect by showing observed and modelled data from a microseismic episode at Schefferville, Quebec (SCHQ), and Deer Lake, Newfoundland (DRLN), with the model data coming from simulations performed with and without the sea ice. The 'with sea ice' simulations used the monthly mean sea ice coverage for 1985-1994 from v. 2.2 of the Global Sea Ice and Sea Surface Temperature dataset (Rayner et al. 1996); the wave model was configured to generate waves only where ice coverage were less than $50 \%$. This was compared with a 'no ice' model. Satellite observation (from the National Oceanographic and Atmospheric Administration National Sea Ice Data Center, http://nsidc.org) shows that by December 2003 the actual $50 \%$ sea ice coverage location had retreated $300-400 \mathrm{~km}$ northwest from the 1985-1994 mean December position (figure $7 a$ ). This change would have substantial effects on the wave generation during periods of strong northwest winds and on the potential for large values of $\Psi$ in the southern Labrador Sea. The results in figure 7 suggest that the low bias in the 'with ice' simulation results reflect the fact that the edge of the prescribed sea ice was too far south, which caused the elimination of the microseism episode from the model. Once this error was corrected, the theory was successful in modelling a microseismic episode generated locally within the Labrador Sea. An interesting implication of this is that seismic stations with a long time history near the edge of the sea ice can be used for long-term monitoring of changes in the sea ice coverage.

\section{Discussion and conclusions}

In the work presented here, the theory of the origin of ocean microseisms in a compressible ocean has been tested against seismic observations and global WAM predictions. It was observed that the North Pacific Ocean is a less efficient deep microseismic generator than the North Atlantic Ocean, where the ocean depth is right for near acoustic resonance. Analyses of the excitation of ocean microseisms in North America and Western Europe during Northern Hemisphere autumn and winter have revealed a dominant source in the open ocean, typically situated near the southern tip of Greenland, where a combination of strong storms, topographic effects on wind patterns and local bathymetry provide a persistent and efficient source of microseism generation. Opposing groups of waves of same wavelengths, driven by opposing winds, over an ocean region of near acoustic resonance depths, generate Stoneley and Rayleigh waves, which travel thousands of kilometres into the continent and are the dominant source of microseisms in North America. The theory has been successful in quantitatively predicting the timing and amplitudes of ground displacements generated by deep ocean wave-wave interaction in the North Atlantic. It has been established that wave-wave interactions in the North Atlantic are sufficiently energetic to account for the dominant seismic amplitudes in North America.

It would be impossible to infer the nature of the microseism source from a point observation on the ocean bottom, unless it happens to be made at the right place and at the right time, that is, with strong surface wave-wave interactions occurring in a region with a favourable depth. Hence, the lack of direct evidence of microseisms excitation over a specific point measurement on the ocean bottom 
(Orcutt et al. 1993; Bromirski et al. 2005) cannot be used to infer a general absence of deep ocean microseisms, unless the observation happens to take place in the generation area at an opportune time. Attempts at direct measurement of deep ocean microseismic sources should be made in regions where climatological and bathymetric conditions are conducive to microseism generation.

The seismic background noise dominated by oceanic microseisms can be effectively used as a seismic source for tomographic studies of geological properties of the Earth's crust (Shapiro \& Campillo 2004; Shapiro et al. 2005; Weaver 2005; Ritzwoller et al. 2006; Stehly et al. 2006). In these studies, it is generally assumed that the source distribution is random in space, although this assumption has been an acknowledged source of error. As was theorized by Longuet-Higgins (1950), discussed by Tabulevich (1992), and demonstrated here, the seismic recording of ocean microseisms at a given site is typically composed of the sum total of microseisms emanating from several source regions. Here we have shown that, with the use of ocean wave models, deep ocean sources of microseisms can be tracked. This new capability should be used to eliminate a portion of the tomographic error introduced by the randomness assumption.

In this paper, we have made no quantitative estimates of the microseismic energy due to the reflection of waves at the coastline. This is because the reflection coefficient, $R$, is likely to depend on a number of variables, such as the beach slope, the wave height and the state of the tide. Elgar et al. (1994) have shown reflection as high as $18 \%$ of the shoreward energy under optimal conditions, but typically less than $5 \%$. To determine appropriate values of $R$ for each stretch of coastline is likely to require a lengthy investigation, which must be left for the future.

The authors wish to thank Dr Robert Guza of the Scripps Institution of Oceanography and Dr Ernesto Rodriguez of the Jet Propulsion Laboratory, California Institute of Technology, for their insights and suggestions. They also wish to thank Dr Hiroo Kanamori of the Caltech Seismological Laboratory for his helpful comments. Maps were generated using the generic mapping tools (GMTs) software package. Seismic data were analysed using Lawrence Livermore National Laboratory's Seismic Analysis Code (SAC). Seismic data were obtained through the Incorporated Research Institutions of Seismology (IRIS) database and the Canadian National Waveform Archive (NWFA). Data from the following networks were used: Global Seismograph Network (GSN), United States National Seismic Network, the International Deployment of Accelerometers (IDA), the Canadian National Seismograph Network (CNSN), GEOFON, the Caltech Regional Seismic Network and the Berkeley Digital Seismograph Network.

This research was carried out at the Jet Propulsion Laboratory, California Institute of Technology, under a contract with the National Aeronautics and Space Administration and funded through the internal Research and Technology Development Program.

\section{References}

Arendt, S. \& Friits, D. 2000 Acoustic radiation by ocean surface waves. J. Fluid Mech. 415, 1-21. (doi:10.1017/S0022112000008636)

Bromirski, P. D. \& Duennebier, F. K. 2002 The near-coastal microseism spectrum: spatial and temporal wave climate relationships. J. Geophys. Res. 107, 2166. (doi:10.1029/2001JB0000265)

Bromirski, P. D., Duennebier, F. K. \& Stephen, R. A. 2005 Mid-ocean microseisms. Geochem. Geophys. Geosyst. 6, Q04009. (doi:10.1029/2004GC000768)

Caires, S., Sterl, A., Bidlot, J. R., Graham, N. \& Swail, V. 2004 Intercomparison of different wind wave reanalyses. J. Clim. 17, 1893-1913. (doi:10.1175/1520-0442(2004)017<1893:IODWR > 2.0.CO;2) 
Canas, J. \& Mitchell, B. J. 1981 Rayleigh wave attenuation and its variation across the Atlantic Ocean. Geophys. J. R. Astron. Soc. 67, 159-176.

Cessaro, R. K. 1994 Sources of primary and secondary microseisms. Bull. Seismol. Soc. Am. 84, $142-148$.

Cooper, R. I. B. \& Longuet-Higgins, M. S. 1951 An experimental study of the pressure variations in standing water waves. Proc. R. Soc. A 206, 426-435. (doi:10.1098/rspa.1951.0079)

Dahm, T., Tilmann, F. \& Morgan, J. P. 2006 Seismic broadband ocean-bottom data and noise observed with free-fall stations: experiences from long-term deployments in the North Atlantic and the Tyrrhenian sea. Bull. Seismol. Soc. Am. 96, 647-664. (doi:10.1785/0120040064)

Elgar, S., Herbers, T. H. C. \& Guza, R. T. 1994 Reflection of ocean surface gravity waves from a natural beach. J. Phys. Oceanogr. 24, 1503-1511. (doi:10.1175/1520-0485(1994)024<1503:ROOSGW> 2.0.CO;2)

Essen, H., Krueger, F., Dahm, T. \& Grevemeyer, I. 2003 On the generation of secondary microseisms observed in northern and Central Europe. J. Geophys. Res. 108, 2506. (doi:10. 1029/2002JB002338)

Evers, L. G. \& Haak, H. W. 2001 Listening to sounds from an exploding meteor and oceanic waves. Geophys. Res. Lett. 28, 41-44. (doi:10.1029/2000GL011859)

Gertstoft, P., Fehler, M. C. \& Sabra, K. G. 2006 When Katrina hit California. Geophys. Res. Lett. 33, L17308. (doi:10.1029/2006GL027270)

Hasselmann, K. 1963 A statistical analysis of the generation of microseisms. Rev. Geophys. 1, $177-210$.

Haubrich, R. A., Munk, W. H. \& Snodgrass, F. E. 1963 Comparative spectra of microseisms and swell. Bull. Seismol. Soc. Am. 53, 27-37.

Kalnay, E. et al. 1996 The NMC/NCAR 40-year reanalysis project. Bull. Am. Meteor. Soc. 77, 437-471. (doi:10.1175/1520-0477(1996)077<0437:TNYRP > 2.0.CO;2)

Kibblewhite, A. C. \& Wu, C. Y. 1996 Wave interactions as a seismo-acoustic source. Lecture Notes in Earth Sciences. Berlin, Germany: Springer.

Langston, C. A. 1989 Scattering of long-period Rayleigh waves in Western North America and the interpretations of coda $Q$ measurements. Bull. Seismol. Soc. Am. 79, 774-789.

Longuet-Higgins, M. S. 1950 A theory of the origin of microseisms. Phil. Trans. R. Soc. A 243, 1-35. (doi:10.1098/rsta.1950.0012)

Mitchell, B. J. 1973 Surface-wave attenuation and crustal anelasticity in Central North America. Bull. Seismol. Soc. Am. 63, 1057-1071.

Mitchell, B. J. 1975 Regional Rayleigh wave attenuation in North America. J. Geophys. Res. 80, 4904-4916.

Mitchell, B. J., Leite, L. W. B., Yu, Y. K. \& Herrmann, R. B. 1976 Attenuation of love and Rayleigh waves across the Pacific at periods between 15 and 110 seconds. Bull. Seismol. Soc. Am. 66, 1189-1202.

Moon, I. J., Ginnis, I., Hara, T., Tolman, H. L., Wright, C. W. \& Walsh, E. J. 2003 Numerical simulation of sea surface directional wave spectra under hurricane wind forcing. J. Phys. Oceanogr. 33, 1680-1706.

Moore, G. W. K. \& Renfrew, I. A. 2005 Tip jets and barrier winds: a QuickSACT climatology of high wind speed events around Greenland. J. Clim. 18, 3713-3725. (doi:10.1175/JCLI3455.1)

Orcutt, J. A., Cox, C. S., Kibblewhite, A. C., Kuperman, W. A. \& Schnidt, H. 1993 Observations and causes of ocean and seafloor noise at ultra-low and very-low frequencies. In Natural physical sources of underwater sound, pp. 203-232. Dordrecht, The Netherlands: Kluwer Academic Publishing.

Rayner, N. A., Horton, E. B., Parker, D. E., Folland, C. K. \& Hackett, R. B. 1996 Version 2.2 of the global sea-ice and sea surface temperature data set, 1903-1994, CRTN 74, available from Hadley Centre, UK Met Office, Met Office, FitzRoy Road, Exeter, Devon, EX1 3PB, UK.

Ritzwoller, M., Barmin, M., Bensen, G., Levshin, A., McCoy, C., Moschetti, M., Lin, F., Yang, Y. \& Shapiro, N. 2006 Progress in broad-band continental scale ambient noise tomography. Seis. Res. Lett. 77, 293. 
Schulte-Pelkum, V., Earle, P. S. \& Vernon, F. L. 2003 Strong directivity of ocean-generated seismic noise. Geochem. Geophys. Geosyst. 5, Q03004. (doi:10.1029/2003GC000520)

Shapiro, N. M. \& Campillo, M. 2004 Emergence of broadband Rayleigh waves from correlations of the ambient seismic noise. Geophys. Res. Lett. 31, L07614. (doi:10.1029/2004GL019491)

Shapiro, N. M., Campillo, M., Stehly, L. \& Ritzwoller, M. H. 2005 High-resolution surface-wave tomography from ambient seismic noise. Science 307, 1615-1618. (doi:10.1126/science.1108339)

Smith, W. H. F. \& Sandwell, D. T. 1997 Global sea floor topography from satellite altimetry and ship depth soundings. Science 277, 1956-1962. (doi:10.1126/science.277.5334.1956)

Stehly, L., Campillo, M. \& Shapiro, N. M. 2006 A study of the seismic noise from its long-range correlation properties. J. Geophys. Res. 111, B10306. (doi:10.1029/2005JB004237)

Tabulevich, V. N. 1992 Microseismic and infrasound waves. In Research reports in physics. Berlin, Germany: Springer.

Tabulevich, V. N., Anikanova, G. V. \& Chernykh, E. N. 1976 Power, energy and position determination for excitation sources of microseisms in the North Atlantic Ocean from the international data 16018 March, 1968. Acta Univ. Ouluensis Ser. A Sci. Rer. Nat. 43, 83-90.

Tabulevich, V. N., Drugova, L. A. \& Troshina, G. M. 1990 On observations of storm microseismic vibrations by seismic stations in the U.S.S.R. Phys. Earth Planet Int. 63, 209-218. (doi:10.1016/ 0031-9201(90)90020-X)

Tanimoto, T., Ishimaru, S. \& Alvizuri, C. 2006 Seasonality in particle motion of micorseisms. Geophys. J. Int. 166, 253-266. (doi:10.1111/j.1365-246X.2006.0293.x)

Tolman, H. L. 1999 User manual and system documentation of WAVEWATCH-III, version 1.18. NOAA/NWS/NCEP/OMB technical note, no. 166.

Tolman, H. L. 2005 Manual and wave user system documentation of WAVEWATCH-III, ver. 2.22, US Department of Commerce. See http://polar.ncep.noaa.goc/wavewatch/wavewatch.html.

Weaver, R. L. 2005 Information from seismic noise. Science 307, 1568-1569. (doi:10.1126/science. 1109834)

Webb, S. C. 1992 The equilibrium oceanic microseism spectrum. J. Acoust. Soc. Am. 92, 2141-2158. (doi:10.1121/1.405226) 